\title{
The Ties That Bind: Do Brand Attachment and Brand Passion Translate Into Consumer Purchase Intention?
}

\author{
Faheem Gul Gilal ${ }^{1}$, Naeem Gul Gilal2 ${ }^{2}$, Rukhsana Gul Gilal ${ }^{3}$, Zhenxing Gong ${ }^{4}$, \\ Waseem Gul Gilal ${ }^{5}$, Muhammad Nawaz Tunio ${ }^{6}$
}

Submitted: 12.04.2020. Accepted: 9.10.2020

\section{Abstract}

Purpose: Drawing from attachment theory and categorization theory, the present study aims to investigate the effects of brand attachment and brand passion on consumer purchase intention, and to explore the moderation effect of product involvement (i.e.a low-involvement convenience product vs. a high-involvement shopping product) in these relationships.

Design/methodology/approach: To bridge this gap, we recruited $n=205$ young consumers to test the hypotheses using AMOS 24.0 and SPSS 24.0. Exploratory factor analysis, confirmatory factor analysis, structural equation modeling, and moderation analysis techniques were used as data analysis methods.

Findings: Results show that when brand attachment and brand passion were assessed, the brand passion has the highest effect on purchase intention. Moreover, our data reveal that brand attachment is more likely to lead to consumer purchase intention for convenience products, while brand passion is more promising for increasing consumer purchase intention for high-involvement shopping products. Finally, we provide a detailed discussion of how these results can be applied to both research and practice.

Implications: This study offers recommendations for how practitioners can strengthen purchase intentions of convenience and shopping brands in emerging markets.

Originality/value: This study is the first to prove that brand attachment is a driver of purchase intention of low-involvement convenience brands, whereas brand passion is a more prominent predictor of the purchase intention of high-involvement shopping brands.

Keywords: brand attachment, brand passion, purchase intention, product involvement, young consumers.

\section{JEL: M31}

\footnotetext{
1 Department of Business Administration, Sukkur IBA University, Sukkur, Sindh, 65200, Pakistan, e-mail: faheem.gul@iba-suk.edu.pk; https://orcid.org/0000-0002-7635-7642.

2 School of Management, Huazhong University of Science and Technology, 1037 Luoyu Rd, Hongshan, Wuhan, Hubei, China, 430074; e-mail: naeemgulgilal@yahoo.com; https://orcid.org/0000-0001-8761-3093.

3 Department of Business Administration, Sukkur IBA University, Sukkur, Sindh, Pakistan; e-mail: rukhsanagulgilal@yahoo.com; https:// orcid.org/0000-0001-7475-3097.

4 School of Business, Liaocheng University, No.1 Hunan Road, Liaocheng City, Shandong Province, China; e-mail: zxgong118@163.com; https://orcid.org/0000-0002-2781-7577.

5 Sukkur IBA University - Department of Business Administration Sukkur, Sindh Pakistan, e-mail: gwaseemgul@yahoo.com.

6 Alpen-Adria-Universität Klagenfurt, Kärnten, Austria; e-mail: m1tunio@edu.aau.at.
} 


\section{Introduction}

During recent decades, interest in consumer-brand relationships has increased, both among academics and among brand managers and researchers (Paul, 2015; Gilal et al., 2019a). One way to understand these relationships focuses on feelings of attachment and passion (e.g. Park et al., 2010; Gilal et al., 2019b; 2020a), which is what lies at the core of all strong brand relationships (Dhaliwal, Singh, and Paul, 2020). Attachment refers to "long-lasting psychological connectedness between human beings" (Bowlby, 1969). Thomson (2006, p. 105) extends this view to human brands and defines "attachment" as the "intensity of a person's target-specific emotional bond with a human brand." Similarly, consumer scholars view brand passion as a "primarily affective, extremely positive attitude toward a specific brand that leads to the emotional attachment" (Gilal et al., 2018a, p. 91).

Academic research guided by attachment theory suggests that brand attachment is to predict key consumer-brand outcomes such as willingness-to-pay a premium price (WTP), word-of-mouth (WOM), and purchase behavior (Gilal et al., 2020a). Consumer purchase intention - an important feature of consumer behavior -is the term used to describe the willingness of a customer to buy a certain product or service (Gilal et al., 2018c). Marketing research offers mixed evidence regarding the impact of brand attachment on purchase intention (Mazar et al., 2008; Bian and Moutinho, 2009). The first research stream suggests that $65 \%$ of satisfied customers do not remain loyal to a firm's offerings (White et al., 2016). In other words, customer satisfaction is not sufficient and is no guarantee of improved customer purchase behavior (Russo et al., 2016), so satisfied customers may not necessarily be loyal to a firm's products and services (Pleshko and Heiens, 2015). Similarly, other studies documented an insignificant impact of brand attachment on purchase intention (Shah et al., 2012; Raza et al., 2014). In fact, Japutra et al. (2014) report detrimental outcomes of brand attachment, such as oppositional brand loyalty and anti-brand actions. By contrast, the second research stream demonstrates that the strength of attachment (bonding) may predict purchase intention (Kaufmann et al., 2016). A study by Park et al. (2010) that examined consumers' purchase intentions shows a positive relationship between brand attachment and consumers' actual purchase behavior. These mixed results raised the question of whether a brand attachment is sufficient to achieve actual purchases, and to what extent it is guaranteed to do so. To fill this gap, the present study is designed to explore once and for all whether consumer purchase behavior is influenced by brand attachment.

Furthermore, studies show that brand passion is also a predictor of many consumer behavior outcomes, such as WTP a price premium (Swimberghe, Astakhova, and 
Wooldridge, 2014), positive WOM (Herrando et al., 2016; Loureiro et al., 2017), brand engagement, price insensitivity, social network support (Pourazad and Pare, 2015), and brand loyalty (Hemsley-Brown and Alnawas, 2016). However, it remains unclear whether consumer brand passion can be translated into actual purchase behavior. To bridge this gap, we also aim to examine the impact of brand passion on consumer purchase intention.

Moreover, besides exploring the separate effects of brand attachment and brand passion, it is practically important to investigate the joint impacts of brand attachment and brand passion on purchase intention. To fill this gap, we aim to confirm whether brand attachment or brand passion is the most capable of increasing consumer purchase intention.

Finally, this research intends to examine the moderating effect of product involvement on the impact of brand attachment (and brand passion) on purchase intention, under the theoretical lens of categorization theory (CT). Both the authors of CT and its supporters suggest that products can be categorized into low- and high-involvement groups based on their characteristics (Mervis and Rosch, 1981; Candi et al., 2017). In line with this rationale, we should examine whether product involvement (i.e. low- vs. high-involvement products) can contribute to enhance or undermine the impact of brand attachment and brand passion on the purchase intention of young consumers.

In sum, the present research adds to brand management research in multiple ways. First, this research intends to confirm whether a brand attachment is capable of driving consumer purchase intention. Second, we contribute by exploring whether brand attachment or brand passion is the most promising in terms of improving consumer purchase intention. Third, we contribute to the furtherance of prior research by investigating whether product involvement can moderate the impact of brand attachment and brand passion on purchase intention.

In line with earlier cross-sectional studies (Xixiang et al., 2016; Pathen et al., 2017; Chen et al., 2019), we divided the present study into several parts. We began by looking at the importance of brand passion and brand attachment, and by setting out the research questions that our study aims to address. Next, we will give a brief overview of the existing literature and develop a theoretical framework. Third, we will discuss the research methods (e.g. participants, procedures, and survey instruments) that we used to address the research objectives. Fourth, we will present the overall results and then provide a discussion of each hypothesis in detail. Finally, we will conclude by discussing the implications and highlighting the agendas for further research in this area. 


\section{Literature Review}

\section{Brand Attachment and Brand Passion}

The concept of attachment can be traced back to an early study by Harlow (1958), who described attachment as “a personal connection or feeling of kinship.” Later, Bowlby (1969) provided another definition, referring to attachment as a "long-lasting psychological connectedness between human beings." Since then, many scholars extended this view to objects and suggested that individuals can form a strong attachment to a variety of objects, such as animals (Johnson, Garrity, and Stallones, 1992; Zasloff, 1996), places (Williams et al., 1992; Manzo, 2003), favorite objects (Nagy and Koles, 2014; Wallendorf and Arnould, 1988), and gifts (Schultz, Kleine, and Kernan, 1989). Similarly, many marketing scholars in more recently extend this view of brand attachment by referring to it as an emotional connection between people and brands (Thomson, MacInnis, and Park, 2005; Park et al., 2010; Jahn, Gaus, and Kiessling, 2012; Gilal et al., 2020a).

This "passion" has a long philosophical history. As such, Vallerand et al. described a passion for general activities as "a strong inclination toward an activity that individuals love, that they find important, and in which they invest time and energy" (2003, p. 757). Since then, researchers broadened this definition still more, defining passion for branded products and documenting brand passion as "a primarily affective, extremely positive attitude towards a specific brand that leads to the emotional attachment” (Gilal et al., 2018a, p. 91).

Although brand attachment and brand passion share similarities, the two concepts are theoretically distinct from each other and differ in several critical ways. First, brand attachment is an emotional connection between people and brands (Thomson, MacInnis, and Park, 2005), whereas brand passion is viewed as a "positive attitude toward a specific brand" (Gilal et al., 2018a, p. 91). This suggests that brand attachment develops affective and cognitive responses, whereas brand passion develops attitudinal responses (Gilal et al., 2019d). Second, strong brand attachment develops over time and is often based on interactions between a consumer and a brand (Li et al., 1996), whereas brand passion arises from how the brand is internalized in one's identity (Albert, Merunka, and Valette-Florence, 2008; Swimberghe, Astakhova, and Wooldridge, 2014; Gilal et al., 2018d). Third, brand passion is based on evaluative judgment,i.e.a sense of consumer identification toward the brand is critical for establishing a passionate feeling for the brand (Astakhova et al., 2017; Gilal et al., 2018b; D'lima, 2018), whereas brand attachment is based on non-evaluative judgment. Fourth, brand attachment is based on prior brand experiences (Japutra et al., 2014), while these experiences are not necessarily in order to have brand passion. Fifth, brand passion can be harmonious 
(autonomous internalization) or obsessive (controlled internalization), while brand attachment varies in strength from "weak" to "strong" (Japutra et al., 2014).

\section{Hypotheses Development}

As discussed at the outset, purchase intention is captured by different factors. For instance, prior investigations indicate that consumer purchase intention can be brought about, for the most part, by improving perceived quality (Levy and Hino, 2016), celebrity credibility (Zafar and Rafique, 2012), trust (Hsu, Chang, and Chuang, 2015; Vlachos and Vrechopoulos, 2012), brand personality (Louis and Lombart, 2010), economic benefit (Kaufmann et al., 2016), hedonic benefit (Yoo and Lee, 2009), brand credibility (Hanzaee and Taghipourian, 2012), brand loyalty (Vajarodaya and Fernando, 2017), and brand attachment (Chavanat, Martinent, and Ferrand, 2009).

Despite the promising influence of the above variables in capturing consumer purchase intention, the existing literature presents mixed evidence for that influence (Mazar, Amir, and Ariely, 2008; Bian, and Haque, 2020), in as much that one group of researchers has documented that brand attachment has an insignificant impact on purchase intention. For instance, studies by Mazar, Amir, and Ariely (2008) and Bian and Moutinho (2009) show that consumers can act dishonestly and consider it acceptable behavior to use a brand without paying a high price. This finding was further supported by Schmalz and Orth (2012) who reveal that brand attachment would lean toward unethical behavior. Raza et al. (2014) tested the link between brand attachment and purchase behavior to conclude that brand attachment has little influence in boosting purchase behavior among consumers. By contrast, an increasing number of studies document that brand attachment does relate positively to key consumer behavior outcomes. Academic research suggests that brand attachment predicts many consumer behavior outcomes such as positive WOM, loyalty, WTP a premium price, and repurchase intention (Vlachos et al., 2010; Levy and Hino, 2016). In particular, studies guided by attachment theory link brand attachment to purchase behavior. For instance, a study by Schmalz and Orth (2012) investigated customer purchase behavior to demonstrate that brand attachment significantly enhances purchase behavior. Bidmon (2017) and Japutra et al. (2014) reveal that consumer purchase intention relating to original brands is significantly boosted by brand attachment. A recent cross-sectional research linking brand attachment to purchase intention reports that brand attachment is a prominent driver of consumer purchase behavior (Kaufmann et al., 2016). In light of the above empirical evidence and the theoretical logic of attachment theory, the current study hypothesizes that consumer purchase intention can be captured by brand attachment. Therefore, we expect that: 
H1: Brand attachment relates positively to consumer purchase intention.

Both researchers and marketers note the significance of brand passion and reveal that brands that succeeded in creating emotional bonds with their customers (i.e. brand passion) are likely to see an improvement in consumer behavior outcomes (Gilal et al., 2018a; 2018b; 2019b). For instance, a study by Swimberghe, Astakhova, and Wooldridge (2014) examine consumers' WTP a premium price to show that it is significantly enhanced by consumer brand passion. Empirical studies that investigate positive WOM by Loureiro et al. (2017) and Herrando et al. (2016) demonstrate that a consumer's brand passion significantly relates to their intention to recommend the target brand. Pourazad and Pare (2015) and Hemsley-Brown and Alnawas (2016) studied the impact of brand passion on consumer buying behavior to confirm that brand passion significantly enhances customer engagement, price insensitivity, and social network support. Looking collectively at the relevance of the above literature, it seems likely that brand passion can play an essential role in exploring how a consumer's passion for a brand influences the consumer's purchase intention. Therefore, we expect that brand passion will have a considerable impact on purchase intention. Thus, we propose that:

H2: Brand passion relates positively to consumer purchase intention.

Besides these direct effects, we may also expect to see an indirect effect of brand attachment and brand passion on consumer purchase intention through product involvement. Academic research guided by categorization theory classifies products as high-or low-involvement based on their characteristics (Mervis and Rosch, 1981; Candi et al., 2017). High-involvement products are those shopping products whose purchase decision involves an extensive thought process beforehand; they usually represent the consumer's lifestyle, personality, and self-image (Candi et al., 2017; Stewart et al., 2019). Examples include buying a super-expensive new Richard Mille watch as worn by Jay-Z, ora new-model Mercedes-Benz. Conversely, low-involvement products are those convenience products that reflect routine purchase decisions (Bart, Stephen, and Sarvary, 2014; Candi et al., 2017), such as buying Bright detergent, Lux soap, Glow \& Lovely cream, or Sunsilk shampoo.

Numerous studies note the promising effect of product involvement in strengthening key consumer behavior outcomes. For example, Bower and Landreth (2001) and Lee and Thorson (2008) demonstrate that product involvement has a considerable moderation effect on the relationship between endorser credibility and consumer purchase responses. Suh and Youjae (2006) explore the moderation effect of product involvement and show that high-involvement products positively improve the effect of advertisement 
attitudes on corporate image. Jain et al. (2010) note significant attitudes among consumers toward high-involvement products. Kaufmann et al. (2016) explore the moderation of product involvement and concluded that high product involvement can affect the impact of actual self-congruence on brand attachment. Petty and Cacioppo (1986) find that high product involvement specifically requires more cognitive effort from consumers. Meanwhile, when the degree of product involvement is low, consumers are reluctant to evaluate the information extensively and therefore do not invest their cognitive efforts in product assessment. Due to low involvement, the product's worth is not perceived so highly by consumers, as they are less motivated to evaluate the novel features and technical capabilities of the product. Therefore, product involvement has a strong influence on brand attachment outcomes, specifically on purchase intention, and especially when products have higher risk factors attached to them and are more emotionally charged. In light of the above literature, we posit that product involvement can play a significant role in moderating the effects of brand attachment and brand passion on consumer purchase intention. In particular, the effect of brand attachment will be stronger for low-involvement convenience products than for high-involvement shopping products. By contrast, the impact of brand passion will be greater for high-involvement products than for low-involvement products. Thus, we expect that:

H3a: The impact of brand attachment on consumer purchase intention will be much stronger for low- than for high-involvement products.

H3b: The impact of brand passion on consumer purchase intention will be much stronger for high- than for low-involvement products.

In light of the above discussion, we developed the following theoretical framework (Figure 1) to be tested using data from young consumers of an emerging market.

Figure 1. Proposed theoretical framework

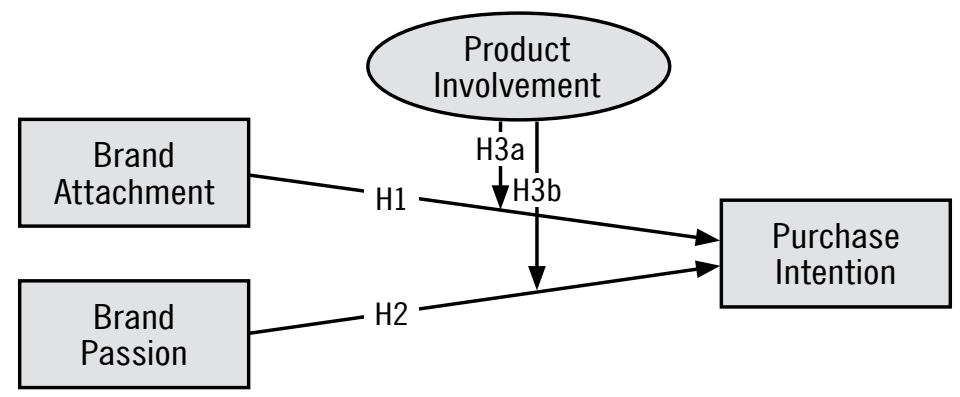

Source: own elaboration. 


\section{Research Methodology}

\section{Participants and the Procedure}

Based on the non-probability sampling technique, we contacted young consumers in two ways. First, subjects were approached in major Pakistan supermarkets. Second, we approached students during brand management/marketing lectures in Pakistan business schools located in Karachi, Hyderabad, Sukkur, and Khairpur. Initially, 300 questionnaires were distributed, and after scanning the returned surveys, 95 responses with missing data were removed. The final sample size was 205 (62.90\% male, mean 24.00 years of age, $S D=3.87$ ). The ratio of $1: 10$ was maintained as per the sample size criterion defined by Hair et al. (1998). See Table 1 for detailed respondents' demographics.

\section{Table 1. Demographic characteristics}

\begin{tabular}{|c|c|c|}
\hline Categories & Items & $\%$ \\
\hline \multirow{2}{*}{ Gender } & Male & $62.90 \%$ \\
\hline & Female & $37.10 \%$ \\
\hline \multirow{2}{*}{ Age } & M & 24.00 \\
\hline & SD & 3.87 \\
\hline \multirow{2}{*}{ Marriage } & Single & $75.60 \%$ \\
\hline & Married & $24.40 \%$ \\
\hline \multirow{4}{*}{ Education } & School & $1.00 \%$ \\
\hline & College & $20.50 \%$ \\
\hline & Bachelors & $47.30 \%$ \\
\hline & Masters & $31.20 \%$ \\
\hline \multirow{4}{*}{ Profession } & Student & $63.40 \%$ \\
\hline & Job in Government Sector & $8.30 \%$ \\
\hline & Job in Private Sector & $16.10 \%$ \\
\hline & Running Business & $12.20 \%$ \\
\hline \multirow{5}{*}{ Income (Monthly) } & Under 5,000 PKR & $62.40 \%$ \\
\hline & $5,000-10,000$ PKR & $1.00 \%$ \\
\hline & $10,000-30,000$ PKR & $0.50 \%$ \\
\hline & $30,000-50,000$ PKR & $5.40 \%$ \\
\hline & 50,000 PKR and above & $30.70 \%$ \\
\hline
\end{tabular}

Source: own elaboration. 
Participants were given questionnaires and asked to think about a brand (s) to which they are attached - or for which they are passionate about - or to choose from Nescafé, Clean \& Clear Shampoo, Lux Soap, Surf Excel, Pepsi, Q Mobile, Bata Shoes, Sony TV, Junaid Jamshed (a clothing brand), or Canon Camera and think about which of these brands they are particularly attached to and would like to buy. Next, participants were asked to fill out surveys that mapped the endogenous variable (i.e.purchase intention), the exogenous variable (i.e. brand attachment and brand passion), and the moderating (i.e.product involvement) variable.

\section{Measures}

Like many marketing studies, we borrowed all scales from prior research (Gilal et al., 2019d; 2019e). Consumers' purchase intentions were assessed using Homburg, Schwemmle, and Kuehnl's (2015) three-item scale, and the responses were recorded on a scale from 1 (definitely would not buy) to 5 (definitely would buy). We used three items to measure brand attachment, borrowed from Ilicic and Webster's (2014) study, already been implemented by marketing researchers (Gilal et al., 2020a). Likewise, subjects indicated their brand passion with ten items borrowed from Gilal et al. (2018a, 2018b). Cronbach's alphas of consumer purchase intention ( $\alpha=0.944)$, brand attachment $(\alpha=0.878)$, and brand passion $(\alpha=0.977)$ were above there commended minimum value of 0.70 (Hair et al., 1998). Finally, based on a focus group discussion with three professors of marketing, we decided to choose ten brands: Nescafé, Clean \& Clear Shampoo, Lux Soap, Surf Excel, Pepsi, Q Mobile, Bata Shoes, Sony TV, Junaid Jamshed (a clothing brand), and Canon Camera. The selection was based on acceptance of the brands in the Pakistani context, the first five were low-involvement convenience brands, while the latter five were high-involvement shopping brands. We manipulated product category/involvement by giving respondents the above list of brands. They were asked to choose one brand to which they are attached and which they would love to buy and use. We operationalized product category/involvement as 1 = "low involvement" (i.e. convenience brands) and 2 = "high involvement" (i.e. shopping brands).

\section{Exploratory Factor Analysis (EFA)}

We first conducted an EFA to test the applicability of each item in the present study's settings. Our data reveal a three-factor solution, explaining $84.19 \%$ of the total variance. As reflected in Table 2, the Kaiser-Meyer-Olkin value was 0.948, and Bartlett's test of sphericity $\left(\chi^{2}(120)=3717.517, p<.001\right)$ was significant. Collectively, the EFA results confirm the appropriateness of the data sample for factor analysis (Reio and Shuck, 2015). 
Table 2. Exploratory factor analysis for the three-factors model

\begin{tabular}{|c|c|c|c|c|c|}
\hline Factors & $\begin{array}{l}\text { Factor } \\
\text { Loading }\end{array}$ & $\begin{array}{l}\% \text { of Variance } \\
\text { Explained }\end{array}$ & Eigen-Value & $\begin{array}{l}\text { Cumulative } \\
\% \text { of Variance }\end{array}$ & $\begin{array}{c}\text { Cronbach } \\
\boldsymbol{\alpha}\end{array}$ \\
\hline Factor 1 & & 49.42 & 7.91 & 49.42 & .977 \\
\hline \multicolumn{6}{|c|}{ Brand Passion } \\
\hline BP6 & .881 & & & & \\
\hline BP5 & .878 & & & & \\
\hline BP2 & .876 & & & & \\
\hline BP1 & .875 & & & & \\
\hline BP4 & .872 & & & & \\
\hline BP3 & .967 & & & & \\
\hline BP8 & .967 & & & & \\
\hline BP10 & .961 & & & & \\
\hline BP7 & .859 & & & & \\
\hline BP9 & .847 & & & & \\
\hline Factor 2 & & 18.26 & 2.92 & 67.68 & .944 \\
\hline \multicolumn{6}{|c|}{ Purchase Intention } \\
\hline PI1 & .899 & & & & \\
\hline PI2 & .885 & & & & \\
\hline PI3 & .881 & & & & \\
\hline Factor 3 & & 16.51 & 2.64 & 84.19 & .878 \\
\hline \multicolumn{6}{|c|}{ Brand Attachment } \\
\hline BA2 & .889 & & & & \\
\hline BA3 & .869 & & & & \\
\hline BA1 & .845 & & & & \\
\hline
\end{tabular}

Note: Kaiser-Meyer-Olkin $=0.948$; Bartlett's Test of Sphericity $=3717.517: \mathrm{p}<0.001 ; \mathrm{df}=120$.

Source: own elaboration. Confirmatory Factor Analysis (CFA).

Next, we conducted a CFA to inspect the suitability of our three-factor model. To this end, we employed a procedure from past research (see Gilal et al., 2018d) to compare a three-factor model (i.e. brand attachment, brand passion, and purchase intention) with other nested models. Our results established that the three-factor model fits the data better than alternative models (see Figure 2), confirming the uniqueness of each variable under scrutiny. Table 3 displays the detailed results. 
Table 3. Model comparison: discriminant validity

\begin{tabular}{|l|r|r|r|r|r|r|r|}
\hline \multicolumn{1}{|c|}{ Model } & $\mathbf{X}$ (2) & df & CFI & TLI & IFI & SRMR & RMESA \\
\hline 3-Factors (BA, BP, PI) & 1.42 & 101 & .988 & .989 & .989 & .029 & .046 \\
\hline 2-Factors (BA/BP combined) & 4.16 & 103 & .912 & .898 & .913 & .060 & .124 \\
\hline 1-Factor (BA/BP/PI combined) & 8.35 & 104 & .974 & .762 & .795 & .140 & .190 \\
\hline
\end{tabular}

Note: $\mathrm{BA}=$ Brand attachment; $\mathrm{BP}=$ brand passion; $\mathrm{PI}=$ purchase intention. Source: own elaboration.

Figure 2. Confirmatory factor analysis

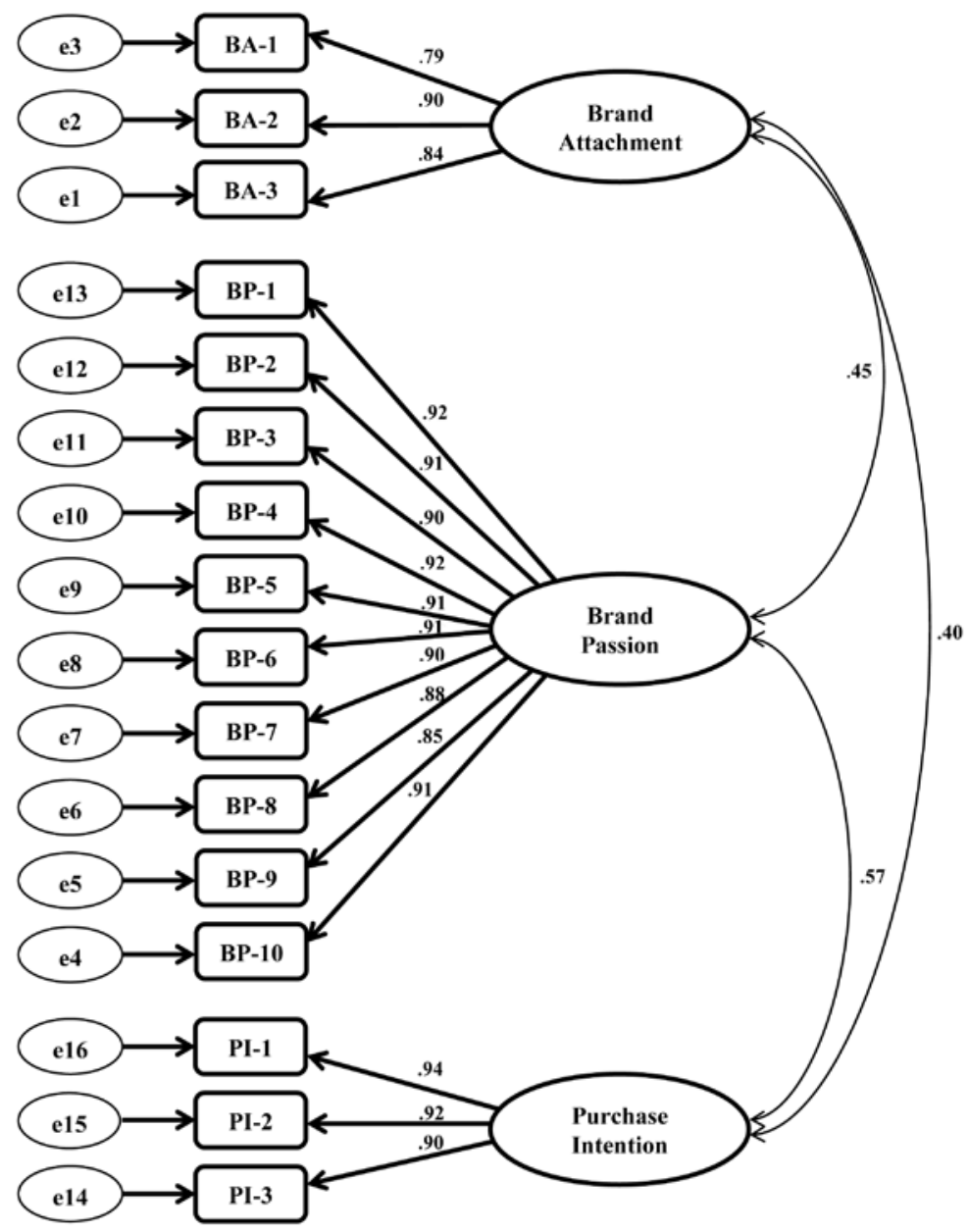

Source: own elaboration. 


\section{Bivariate Correlation}

Table 4 presents the findings of the bivariate analysis, which shows that brand attachment correlates significantly with consumer purchase intention $\left(r=0.365^{* * *}\right)$. Likewise, brand passion correlates strongly to consumer purchase intention $\left(r=0.416^{* * *}\right)$. The results further indicate that the correlation between brand attachment and brand passion is significantly positive $\left(\mathrm{r}=0.547^{* * *}\right)$. These findings generally support the theory that consumer purchase intention is significantly influenced by brand attachment (and brand passion).

Table 4. Descriptive statistics

\begin{tabular}{|l|l|l|l|c|c|c|}
\hline \multicolumn{1}{|c|}{ Variables } & M & SD & $\boldsymbol{\alpha}$ & $\begin{array}{c}\text { Brand } \\
\text { attachment }\end{array}$ & $\begin{array}{c}\text { Brand } \\
\text { passion }\end{array}$ & $\begin{array}{c}\text { Purchase } \\
\text { intention }\end{array}$ \\
\hline Brand Attachment & 4.539 & 0.674 & .878 & 1 & \\
\hline Brand Passion & 4.258 & 1.047 & .977 & $.416 * \star$ & 1 & 1 \\
\hline Purchase Intention & 4.038 & 1.188 & .944 & $.365^{\star \star}$ & $.547 * *$ & 1 \\
\hline
\end{tabular}

Note: ${ }^{* *} \mathrm{p}<0.01,{ }^{*} \mathrm{p}<0.05$

Source: own elaboration.

\section{Structural Equation Modeling (SEM)}

Next, we conducted SEM to explore whether brand attachment or brand passion is more important in predicting consumer purchase intention. The indexes of the proposed SEM demonstrated an excellent fit: $\mathrm{CMIN} / \mathrm{DF}=1.424$; $\mathrm{CFI}=0.988$; $\mathrm{RFI}=0.962$; $\mathrm{NFI}=0.97 ; \mathrm{TLI}=0.986 ; \mathrm{SRMR}=0.029 ; \mathrm{RMSEA}=0.046 ;$ PCLOSE $=0.654$; $\mathrm{AIC}=213.83$. See Figure 3 for the detailed results.

Hypothesis 1, presented in Figure 3, proposes a significantly positive link between brand attachment and purchase intention. Our data support this view $\left(\beta=0.18^{* *}\right)$. Similarly, Hypothesis 2 posits that there is a significant positive association between brand passion and consumer purchase intention $\left(\beta=0.50^{* * *}\right)$. This theory is further supported by our data, which indicates that brand passion significantly improves consumer purchase intention. Collectively, the SEM findings show that both brand attachment and brand passion have a considerable influence on consumer purchase intention (see Table 5). 
Figure 3. Estimated theoretical framework

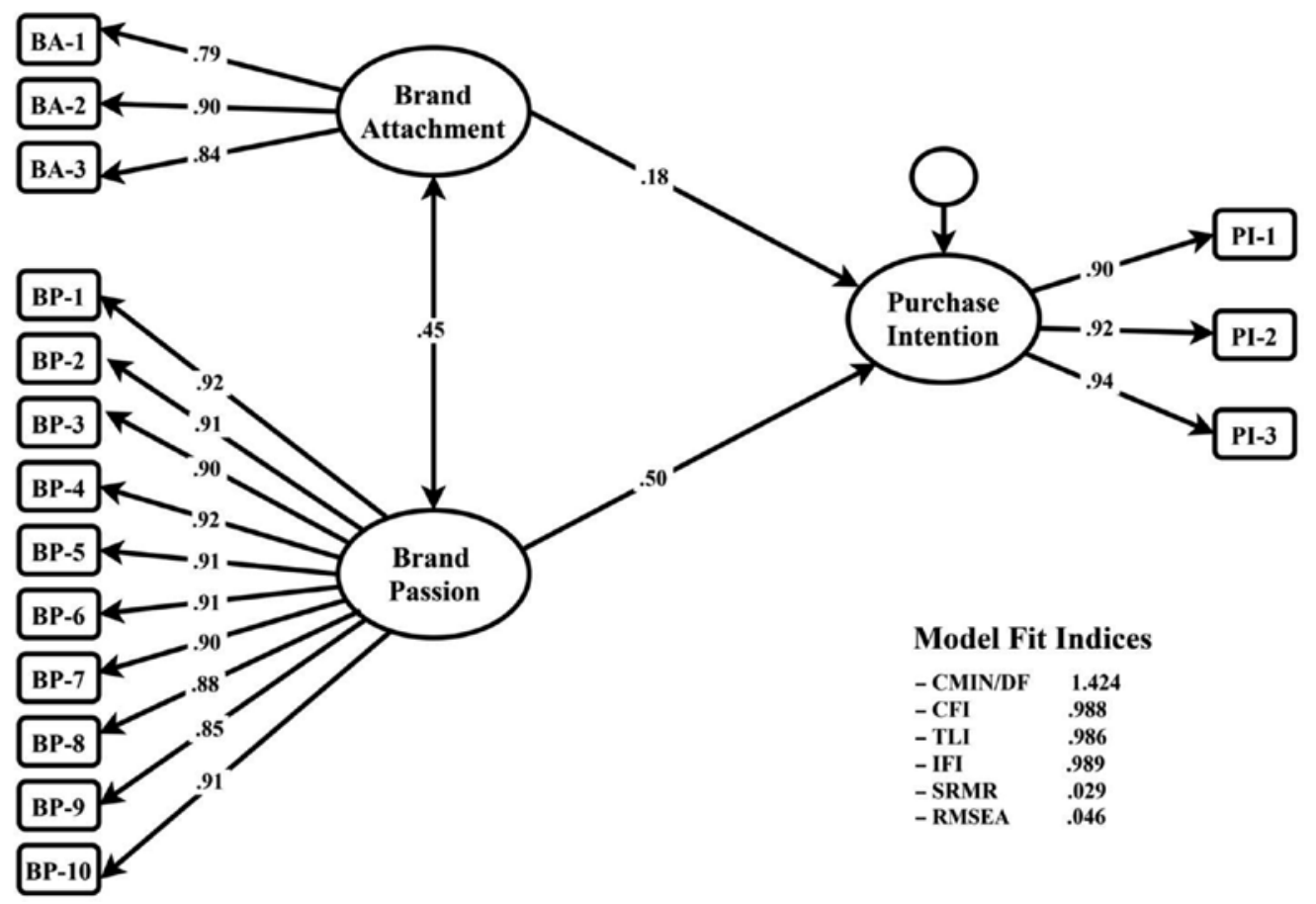

Source: own elaboration.

Table 5. Hypotheses testing

\begin{tabular}{|c|l|c|c|}
\hline H & \multicolumn{1}{|c|}{ Hypothesized Relationship } & Beta & CR \\
\hline H1 & Brand Attachment $\rightarrow$ Purchase Intention & $0.18 * *$ & 2.46 \\
\hline H2 & Brand Passion $\rightarrow$ Purchase Intention & $0.50 * * *$ & 6.90 \\
\hline
\end{tabular}

Note: $* * * p<.001,{ }^{* *} \mathrm{p}<0.01 ; \mathrm{CR}=$ critical ratio.

Source: own elaboration.

\section{Moderating Effect of Product Involvement}

We tested Hypotheses 3a and 3b, which concern the moderating effect of product involvement, using the procedure endorsed by Preacher, Rucker, \& Hayes (2007). Our data confirm Hypothesis 3a, which posits that the effect of brand attachment on consumer purchase intention is moderated by product involvement $\left(\beta=-0.499^{*}\right)$. We then conducted the analysis recommended by Aiken, West, and Reno (1991) to examine 
whether the impact of brand attachment on purchase intention is more prominent for low - than high-involvement products. Our results, presented in Figure 4, indicate that consumer purchase intention is better captured by brand attachment when product involvement is low $\left(\beta=0.950^{* * *}\right.$ : $\mathrm{CI}=0.575$ to 1.325$)$ than when product involvement is high ( $\beta=0.451^{* *}$ : $\mathrm{CI}=0.168$ to 0.733 ). In other words, brand attachment has better results in improving consumer purchase intention for convenience products than for shopping products (see Table 6).

Figure 4. Two-way interaction effects of brand attachment by product involvement on purchase intention

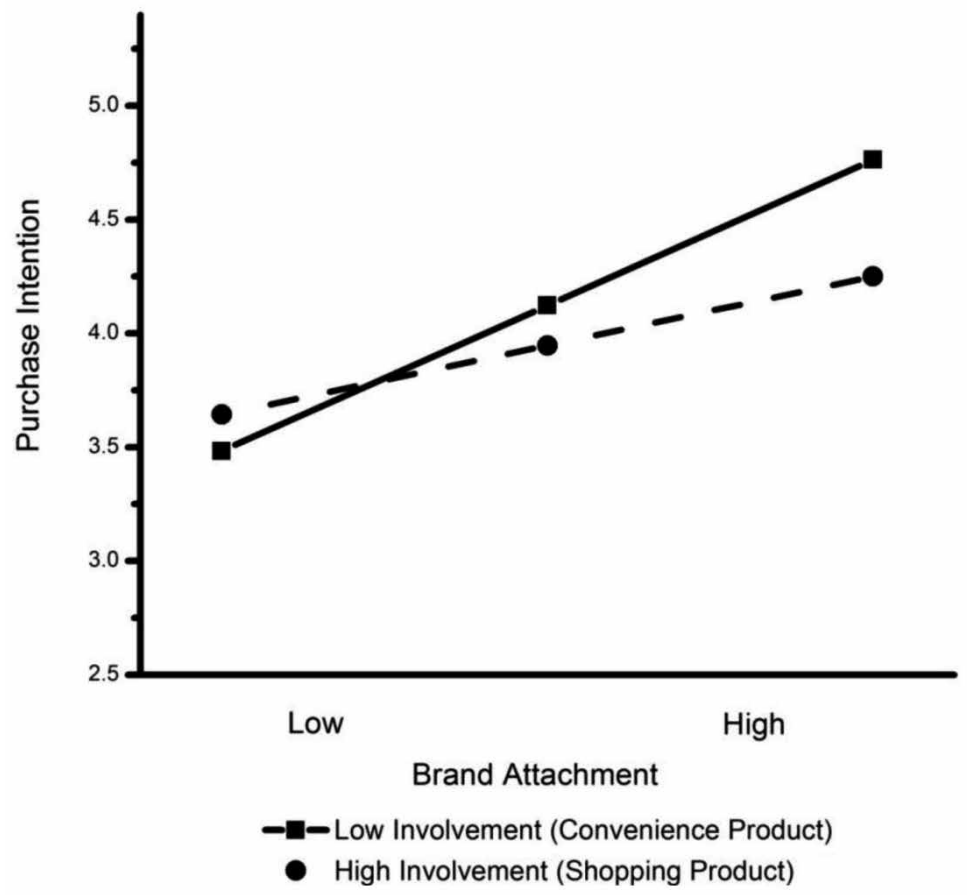

Source: own elaboration.

Similarly, H3b posits that the effect of brand passion on purchase intention is moderated by product involvement. Our data reveal a considerable interaction effect of brand passion and product involvement on purchase intention $\left(\beta=0.287^{\star}\right)$. Consequently, H3b is confirmed. We further employed a procedure recommended by Aiken, West, and Reno (1991) to investigate whether the relationship is more prominent for low - or high-involvement products. Our results (see Figure 5) revealed that consumer purchase intention is strengthened more by brand passion when product involvement is high $\left(\beta=0.726^{* * *}: \mathrm{CI}=0.558\right.$ to 0.894$)$ than for a low-involvement product $\left(\beta=0.439^{* * *}\right.$ : 
$\mathrm{CI}=0.224$ to 0.654 ). Together, these findings clearly show that brand attachment is an important criterion for boosting consumer purchase intention for convenience products, while brand passion is an important criterion for improving purchase intention for shopping products.

Table 6. Moderation effect of product involvement

(a) Brand attachment as an independent variable

\begin{tabular}{|c|c|c|c|c|c|c|}
\hline Predictor & $\boldsymbol{\beta}$ & $t$ & $p$ & $\boldsymbol{F}$ & \multicolumn{2}{|c|}{$R^{2}$ (Change $\left.R^{2}\right)$} \\
\hline Product Involvement & 2.09 & 1.90 & .058 & \multirow{3}{*}{12.52} & \multirow{3}{*}{\multicolumn{2}{|c|}{$.157(.018)$}} \\
\hline Brand Attachment & 1.45 & 3.56 & .000 & & & \\
\hline Brand Attachment xProduct Involvement & -0.499 & 2.10 & .037 & & & \\
\hline Product Involvement 1 SD & $\begin{array}{c}\text { Conditional } \\
\text { Effect }\end{array}$ & SE & $z$ & $P$ & $L L C I$ & ULCI \\
\hline Low Involvement (Convenience Product) & .950 & .190 & 4.99 & .000 & .575 & 1.325 \\
\hline High Involvement (Shopping Product) & .451 & .143 & 3.14 & .002 & .168 & .733 \\
\hline
\end{tabular}

(b) Brand passion as an independent variable

\begin{tabular}{|c|c|c|c|c|c|c|}
\hline Predictor & $\boldsymbol{\beta}$ & $t$ & $p$ & $\boldsymbol{F}$ & \multicolumn{2}{|c|}{$R^{2}$ (Change $R^{2}$ ) } \\
\hline Product Involvement & -1.29 & -2.11 & .036 & \multirow{3}{*}{36.80} & \multirow{3}{*}{\multicolumn{2}{|c|}{$.315(.015)$}} \\
\hline Brand Passion & .152 & .649 & .517 & & & \\
\hline Brand Passion x Product Involvement & .287 & 2.07 & .039 & & & \\
\hline Product Involvement 1 SD & $\begin{array}{c}\text { Conditional } \\
\text { Effect }\end{array}$ & $S E$ & $z$ & $P$ & LLCI & $U L C I$ \\
\hline Low Involvement (Convenience Product) & .439 & .109 & 4.03 & .000 & .224 & .654 \\
\hline High Involvement (Shopping Product) & .726 & .085 & 8.53 & .000 & .558 & .894 \\
\hline
\end{tabular}

Source: own elaboration.

\section{Discussion of Results}

The present study is the first attempt to simultaneously determine the impacts of brand attachment and of brand passion on purchase intention in an emerging market. We add to brand management research in various ways. First, this study attempted to confirm whether a brand attachment is capable of producing purchase intention in consumers. 
Second, we contributed by exploring whether brand attachment or brand passion is a stronger predictor of actual purchase intention. Third, this study contributed to the examination of whether the impact of brand attachment and brand passion on the purchase intent of younger consumers is moderated by product involvement.

Consistent with expectations, our data reveals that consumer purchase intention does derive from brand attachment. Although this finding differs from some published studies (Mazar, Amir, and Ariely, 2008; Rizwan et al., 2013; Japutra et al., 2014), it is consistent with those of Schmalz and Orth (2012), Levy and Hino (2016), Japutra et al. (2014), and Bidmon (2017), which significantly link brand attachment to consumers' behavioral responses such as purchase behavior, WOM, brand loyalty, intention to revisit, and brand trust, respectively.

Figure 5. Two-way interaction effects of brand passion by product involvement on purchase intention

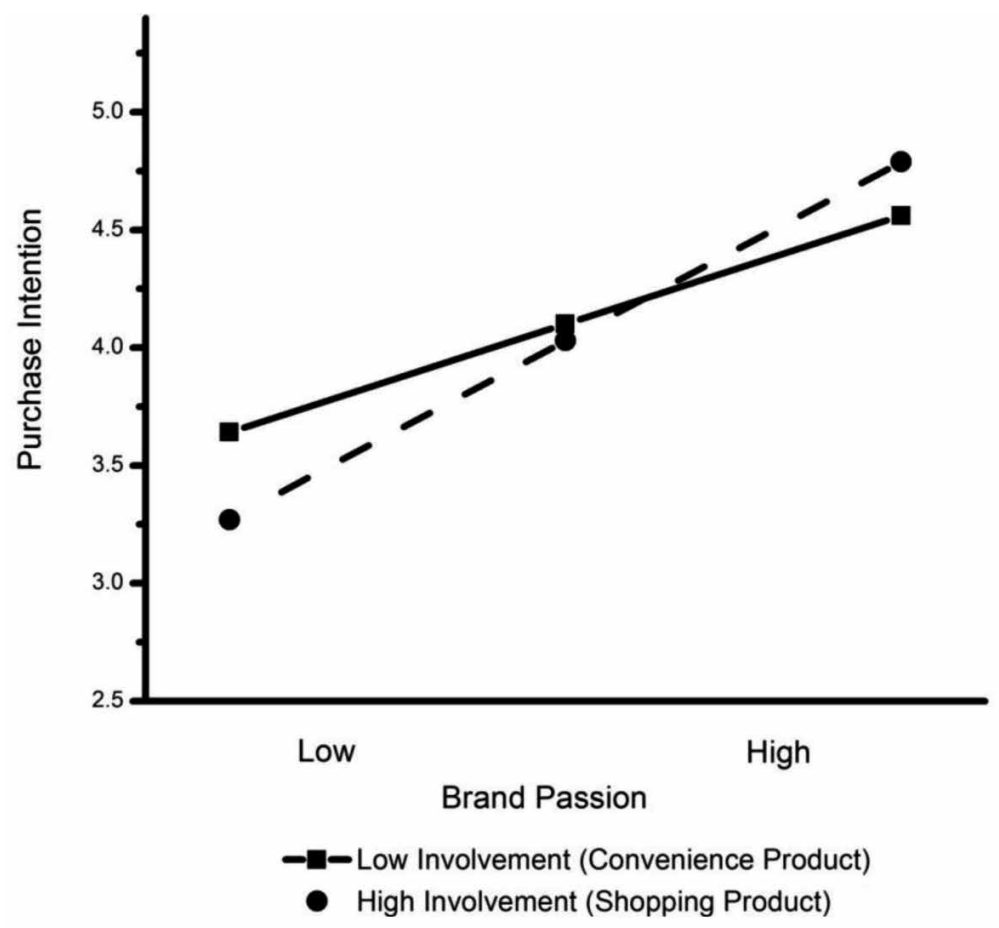

Source: own elaboration.

Furthermore, our results show that brand passion had the strongest impact on young consumers' purchase intentions. This finding confirms the results of many marketing 
scholars, who suggested that consumer brand passion positively enhances WTP a price premium, WOM, intention to play a digital game, and brand loyalty (Back, Lee, and Stinchfield, 2011; Albert, Merunka, and Valette-Florence, 2013; Herrando, Jiménez-Martínez, and Martín-De, 2016; Hemsley-Brown and Alnawas, 2016).

Moreover, the results of our moderation analysis reveal that both brand attachment and brand passion significantly improved consumer purchase intention for both low-and high-involvement products. However, while brand attachment relates positively to consumer purchase intention, this relationship is more promising for low-involvement convenience products than for high-involvement shopping products. Conversely, brand passion appears to be more important for boosting consumer purchase intention with regard to high-involvement shopping. Although these findings are consistent with Lee, Cheng, and Shih (2017) and Stewart et al. (2019), they differ from some published studies (Bart, Stephen, and Sarvary, 2014; Candi et al., 2017) that indicate that consumer attitude and purchase intention result from both high-involvement convenience products and low-involvement shopping products. Collectively, these results clearly show that brand attachment is an important criterion for increasing consumer purchase intention with regard to convenience products, whereas brand passion is a more important criterion for improving purchase intention for shopping products.

\section{Research Implications}

Our study contributes both theoretically and practically to this growing body of brand management research in several ways. First, we link brand attachment (and brand passion) to consumer purchase intention under the theoretical framework of attachment theory. Our findings disclose that both brand attachment and brand passion significantly increase purchase intention among young consumers. Therefore, we help to broaden the theoretical logic of attachment theory by indicating that consumer purchase intention can be increased in emerging markets by capturing young consumers' brand attachment and brand passion.

Second, our research supports the validity of the categorization theory (CT) in emerging markets. The authors of the CT and its supporters suggest that products can be categorized into low- and high-involvement items based on their characteristics (Candi et al., 2017; Mervis and Rosch, 1981). In the light of the CT, we studied the moderation of product involvement on the association between brand attachment (and brand passion) and consumer purchase intention. Particularly, our study illuminated that 
- while brand attachment is an important criterion for increasing purchase intention for both categories of products -its impact is more promising for low-involvement convenience products than for high-involvement shopping products. Conversely, brand passion relates the most positively to young consumers' purchase intentions regarding high-involvement shopping products. Accordingly, our contribution helps to broaden the theoretical notion of CT by reporting the importance of product involvement and how it matters with regard to increasing young consumers' purchase intentions.

Third, our data revealed a positive association between brand attachment and consumer purchase intention. Prior research examining the effect of brand attachment on purchase intention has reported mixed findings. Therefore, this study conclusively establishes the promising role of brand attachment in improving purchase intention. Thus, a brand manager seeking to enhance purchase intention may benefit from considering the framework of this body of knowledge and focusing on consumer attachment.

Fourth, this study confirms that brand passion is the factor that has the strongest impact on consumer purchase intention. Therefore, brand managers wishing to increase purchase intention among young consumers may consider the findings of this study and direct their focus on creating, maintaining, and sustaining brand passion among young consumers.

Fifth, by assessing brand attachment and brand passion, we found that consumer brand passion had the highest impact on purchase intention. Hence, our study is the first to shed light on whether brand attachment or brand passion is the most essential in predicting consumer purchase intention. Thus, brand managers of both high- and low-involvement products who are aiming to increase purchase intention for their brands could profitably consider the findings of this research and focus on creating, maintaining, and enhancing consumer-brand passion.

Finally, our moderation analysis concluded that brand attachment is more effective at improving purchase intention for low-involvement products (i.e. convenience products), while brand passion is more promising for increasing purchase intention for high-involvement products (i.e. shopping products). These findings are valuable for both domestic and international managers seeking to increase purchase intention for convenience and shopping products. For instance, national managers involved in marketing convenience products should focus more on creating brand attachment, while managers of companies marketing shopping products who wish to improve customer purchase intention should focus more on creating brand passion. 


\section{Limitations and Ways Forward}

This study is not without limitations. First, when brand attachment and brand passion were assessed, our research indicated that brand passion had the highest effect on consumer purchase intention. These results should be considered carefully as the sample size of the present study was $n=205$ consumers, which cannot be seen to represent the entire population of Pakistan. Thus, we believe that future research should gather more data and that a longitudinal experimental design would be required to make our results generalizable.

Second, the moderation findings indicate that brand attachment is more promising for boosting purchase intention for low-involvement products, while brand passion is more promising for increasing purchase intention for high-involvement products. Our results provide some guidance as to how to improve consumer purchase intention. However, it is not clear whether brand attachment or brand passion is the most effective factor in increasing purchase intention for convenience versus shopping products in men versus women (Gilal et al., 2018b; Friedmann and Lowengart, 2019; 2019a). Thus, we invite branding scholars to fill this gap by developing moderated-moderation models to compare the impacts of brand attachment and brand passion on young consumers' purchase intentions for convenience versus shopping products for both male and female customers.

An increasing number of international scholars of brand management highlight the significance of age in segmenting, targeting, and positioning. As such, Gilal et al. (2019a) noted that compared to young customers, older customers respond much more strongly to personally and historically nostalgic advertisements with regard to their engagement in brand resurrection movements. Based on this idea, we invite scholars to extend the findings of this research by considering the moderating effect of customer age, so as to better understand how brand attachment and brand passion are linked to purchase intention; that is, whether the impact of brand attachment or brand passion on purchase intention is stronger for younger or older customers. Finally, we deem it interesting to explore the antecedents and outcomes of passion for masstige brands in both emerging and developed market settings (Paul, 2019; Kumar, Paul, and Unnithan, 2020).

\section{Conclusion}

Extant literature presents mixed evidence for the impact of brand attachment on key consumer behavior outcomes. Specifically, one group of researchers noted a signifi- 
cantly positive link between brand attachment and purchase intention, while other researchers documented only a trivial impact of brand attachment on consumer purchase intention. This study conclusively tested a fully-fledged conceptual model comprised of brand attachment and brand passion as independent variables and product involvement as a moderating variable to assess the impact on the purchase intention of young consumers in an emerging market. Our data established that the strongest positive link was between brand passion and purchase intention among young consumers, followed by the effect of brand attachment. Likewise, moderation findings suggested that while brand attachment is positively related to purchase intention, this relationship is more promising for low- than high-involvement products. On the other hand, brand passion is more positively related to young consumers' purchase intentions with regard to high-involvement products than to low-involvement products. In light of these results, our study has conclusively confirmed the respective significances of brand attachment and brand passion in increasing purchase intention among young consumers in an emerging market.

This research was supported by the National Natural Science Foundation of China (71801120), the Ministry of Education of Humanities and Social Science Research youth fund project of China (18YJC630038), and the Shandong Social Science Planning Fund (19CQXJ05).

\section{References}

Ahuvia, A.C. (2005). Beyond the extended self: Loved objects and consumers' identity narratives. Journal of Consumer Research, 32(1), 171-184. https://doi.org/10.1086/429607.

Aiken, L.S., West, S.G., and Reno, R.R. (1991). Multiple regression: Testing and Interpreting Interactions. Sage.

Albert, N., Merunka, D., and Valette-Florence, P. (2008). When consumers love their brands: Exploring the concept and its dimensions. Journal of Business Research, 61(10), 1062-1075. https://doi.org/10.1016/j.jbusres.2007.09.014.

Albert, N., Merunka, D., and Valette-Florence, P. (2013). Brand passion: Antecedents and consequences. Journal of Business Research, 66(7), 904-909. https://doi.org/10.1016/j.jbusres.2011.12.009.

Astakhova, M., Swimberghe, K.R., and Wooldridge, B.R. (2017). Actual and ideal-self congruence and dual brand passion. Journal of Consumer Marketing, 34(7), 664-672. https://doi.org/10.1108/JCM-10-2016-1985.

Back, K.J., Lee, C.K., and Stinchfield, R. (2011). Gambling motivation and passion: A comparison study of recreational and pathological gamblers. Journal of Gambling Studies, 27(3), 355-370. https://doi.org/10.1007/s10899-010-9212-2.

Bart, Y., Stephen, A.T., and Sarvary, M. (2014). Which products are best suited to mobile advertising? A field study of mobile display advertising effects on consumer attitudes and intentions. Journal of Marketing Research, 51(3), 270-285. https://doi.org/10.1509/jmr.13.0503. 
Bian, X., and Moutinho, L. (2009). An investigation of determinants of counterfeit purchase consideration. Journal of Business Research, 62(3), 368-378. https://doi.org/10.1016/j.jbusres.2008.05.012.

Bian, X., and Haque, S. (2020). Counterfeit versus original patronage: Do emotional brand attachment, brand involvement, and past experience matter? Journal of Brand Management, 1-14. https://doi.org/10.1057/s41262-020-00189-4.

Bidmon, S. (2017). How does attachment style influence the brand attachment-brand trust and brand loyalty chain in adolescents? International Journal of Advertising, 36(1), 164-189. https://doi.org/10.1080/02650487.2016.1172404.

Bower, A.B., and Landreth, S. (2001). Is beauty best? Highly versus normally attractive models in advertising. Journal of Advertising, 30(1), 1-12. https://doi.org/10.1080/00913367.2001.10673627.

Bowlby, J. (1969). Attachment and Loss: Attachment; John Bowlby. Basic Books.

Cacioppo, J.T., Petty, R.E., Kao, C.F., and Rodriguez, R. (1986). Central and peripheral routes to persuasion: An individual difference perspective. Journal of Personality and Social Psychology, 51(5), 1032-1043. https://doi.org/10.1037/0022-3514.51.5.1032.

Candi, M., Jae, H., Makarem, S., and Mohan, M. (2017). Consumer responses to functional, aesthetic, and symbolic product design in online reviews. Journal of Business Research, 81, 31-39. https://doi.org/10.1016/j.jbusres.2017.08.006.

Chavanat, N., Martinent, G., and Ferrand, A. (2009). Sponsor and sponsees interactions: Effects on consumers' perceptions of brand image, brand attachment, and purchasing intention. Journal of Sport Management, 23(5), 644-670. https://doi.org/10.1123/jsm.23.5.644.

Chen, C.X., Zhang, J., and Gilal, F.C. (2019). Composition of motivation profiles at work using latent analysis: theory and evidence. Psychology Research and Behavior Management, 12, 811-824. https://doi.org/10.2147/PRBM.S210830.

Dayan, M., and Di Benedetto, C.A. (2010). The impact of structural and contextual factors on trust formation in product development teams. Industrial Marketing Management, 39(4), 691-703. https://doi.org/10.1016/j.indmarman.2010.01.001.

D’lima, C. (2018). Brand passion and its implication on consumer behavior. International Journal of Business Forecasting and Marketing Intelligence, 4(1), 30-42. https://doi.org/10.1504/IJBFMI.2018.10009307.

Dhaliwal, A., Singh, D.P., and Paul, J. (2020). The consumer behavior of luxury goods: a review and research agenda. Journal of Strategic Marketing, 1-27. https://doi.org/10.1080/0965254X.2020.1758198.

Friedmann, E., and Lowengart, O. (2019). Gender segmentation to increase brand preference? The role of product involvement. Journal of Product \& Brand Management, 28(3), 408-420. https://doi.org/10.1108/JPBM-06-2018-1917.

Gilal, F.G., Zhang, J., Gilal, N.G., and Gilal, R.G. (2018a). Association between a parent's brand passion and a child's brand passion: a moderated moderated-mediation model. Psychology Research and Behavior Management, 11, 91-102. https://doi.org/10.2147/PRBM.S161755.

Gilal, F.G., Zhang, J., Gilal, R.G., and Gilal, N.G. (2018b). Linking motivational regulation to brand passion in a moderated model of customer gender and age: an organismic integration theory perspective. Review of Managerial Science. https://doi.org/10.1007/s11846-018-0287-y.

Gilal, N.G., Zhang, J., and Gilal, F.G. (2018c). Linking product design to consumer behavior: the moderating role of the consumption experience. Psychology Research and Behavior Management, 11, 169-185. https://doi.org/10.2147/PRBM.S161384.

Gilal, F.G., Zhang, J., Gilal, N.G., and Gilal, R.G. (2018d). Integrating self-determined needs into the relationship among product design, willingness-to-pay a premium, and word-of-mouth: 
a cross-cultural gender-specific study. Psychology Research and Behavior Management, 11, 227-241. https://doi.org/10.2147/PRBM.S161269.

Gilal, N.G., Zhang, J., Gilal, F.G., and Gilal, R.G. (2019a). Bygone days and memories: the effects of nostalgic ads on consumer brand resurrection movements. Journal of Brand Management, 1-21. https://doi.org/10.1057/s41262-019-00170-w.

Gilal, F.G., Paul, J., Gilal, N.G., and Gilal, R.G. (2019b). Celebrity endorsement and brand passion among air travelers: Theory and evidence. International Journal of Hospitality Management, 1-9. https://doi.org/10.1016/j.ijhm.2019.102347.

Gilal, F.G., Zhang, J., Paul, J., and Gilal, N.G. (2019c). The role of self-determination theory in marketing science: An integrative review and agenda for research. European Management Journal, 37(1), 29-44. https://doi.org/10.1016/j.emj.2018.10.004.

Gilal, F.G., Channa, N.A., Gilal, N.G., Gilal, R.G., and Shah, S.M.M. (2019d). Association between a teacher's work passion and a student's work passion: a moderated mediation model. Psychology Research and Behavior Management, 12, 889-900. https://doi.org/10.2147/PRBM.S212004.

Gilal, F.G., Zhang, J., Gilal, N.G., and Gilal, R.G. (2019e). Linking self-determined needs and word of mouth to consumer e-waste disposal behavior: A test of basic psychological needs theory. Journal of Consumer Behaviour, 18(1), 12-24. https://doi.org/10.1002/cb.1744.

Gilal, F.G., Zhang, J., Gilal, R.G., and Gilal, N.G. (2020a). Integrating intrinsic motivation into the relationship between product design and brand attachment: A cross-cultural investigation based on self-determination theory. European Journal of International Management, 14(1), 1-27. https://doi.org/10.1504/EJIM.2020.103800.

Hair, J.F., Black, W.C., Babin, B.J., Anderson, R.E., and Tatham, R.L. (1998). Multivariate Data Analysis. Upper Saddle River, NJ: Prentice-Hall.

Hanzaee, K.H., and Taghipourian, M.J. (2012). The effects of brand credibility and prestige on consumers' purchase intention in low and high product involvement. Journal of Basic and Applied Scientific Research, 2(2), 1281-1291.

Harlow, H.F. (1958). The nature of love. American Psychologist, 13(12), 673-685. https://doi.org/10.1037/h0047884.

Hemsley-Brown, J., and Alnawas, I. (2016). Service quality and brand loyalty: The mediation effect of brand passion, brand affection, and self-brand connection. International Journal of Contemporary Hospitality Management, 28(12), 2771-2794. https://doi.org/10.1108/IJCHM-09-2015-0466.

Herrando, C., Jiménez-Martínez, J., and Martín-De Hoyos, M.J. (2017). Passion at first sight: how to engage users in social commerce contexts. Electronic Commerce Research, 17(4), 701-720. https://doi.org/10.1007/s10660-016-9251-6.

Hidalgo, M.C., and Hernandez, B. (2001). Place attachment: Conceptual and empirical questions. Journal of Environmental Psychology, 21(3), 273-281. https://doi.org/10.1006/jevp.2001.0221.

Homburg, C., Schwemmle, M., and Kuehnl, C. (2015). New product design: Concept, measurement, and consequences. Journal of Marketing, 79(3), 41-56. https://doi.org/10.1509/jm.14.0199.

Hsu, M.H., Chang, C.M., and Chuang, L.W. (2015). Understanding the determinants of online repeat purchase intention and moderating role of habit: The case of online group-buying in Taiwan. International Journal of Information Management, 35(1), 45-56. https://doi.org/10.1016/j.ijinfomgt.2014.09.002.

Ilicic, J., and Webster, C.M. (2014). Investigating consumer-brand relational authenticity. Journal of Brand Management, 21(4), 342-363. https://doi.org/10.1057/bm.2014.11.

Jahn, S., Gaus, H., and Kiessling, T. (2012). Trust, commitment, and older women: Exploring brand attachment differences in the elderly segment. Psychology \& Marketing, 29(6), 445-457. https://doi.org/10.1002/mar.20533. 
Jain, V., Roy, S., Kumar, A., and Kabra, A. (2010). Differential effects of national vs. regional celebrities on consumer attitudes. Management \& Marketing, 5(4), 121-134.

Japutra, A., Ekinci, Y., and Simkin, L. (2014). Exploring brand attachment, its determinants, and outcomes. Journal of Strategic Marketing, 22(7), 616-630.

https://doi.org/10.1080/0965254X.2014.914062.

Japutra, A., Ekinci, Y., Simkin, L., and Nguyen, B. (2014). The dark side of brand attachment: A conceptual framework of brand attachment's detrimental outcomes. The Marketing Review, 14(3), 245-264. https://doi.org/10.1362/146934714X14024779061875.

Johnson, T.P., Garrity, T.F., and Stallones, L. (1992). Psychometric evaluation of the Lexington attachment to pets scale (LAPS). Anthrozoös, 5(3), 160-175. https://doi.org/10.2752/089279392787011395.

Kaufmann, H.R., Petrovici, D.A., Gonçalves Filho, C., and Ayres, A. (2016). Identifying moderators of brand attachment for driving customer purchase intention of original vs counterfeits of luxury brands. Journal of Business Research, 69(12), 5735-5747.

https://doi.org/10.1016/j.jbusres.2016.05.003.

Keller, K.L. (2014). Consumer brand relationships. Journal of Brand Management, 21(5), 365-365. https://doi.org/10.1057/bm.2014.21.

Kumar, A., Paul, J., and Unnithan, A.B. (2020). 'Masstige' marketing: A review, synthesis, and research agenda. Journal of Business Research, 113, 384-398. https://doi.org/10.1016/j.jbusres.2019.09.030.

Lee, J.G., and Thorson, E. (2008). The impact of celebrity-product incongruence on the effectiveness of product endorsement. Journal of Advertising Research, 48(3), 433-449. https://doi.org/10.2501/S0021849908080446.

Lee, W.I., Cheng, S.Y., and Shih, Y.T. (2017). Effects among product attributes, involvement, wordof-mouth, and purchase intention in online shopping. Asia Pacific Management Review, 22(4), 223-229. https://doi.org/10.1016/j.apmrv.2017.07.007.

Levy, S., and Hino, H. (2016). Emotional brand attachment: a factor in customer-bank relationships. International Journal of Bank Marketing, 34(2), 136-150. https://doi.org/10.1108/IJBM-06-2015-0092.

Li, M.W., Teng, H.Y., and Chen, C.Y. (2020). Unlocking the customer engagement-brand loyalty relationship in tourism social media: The roles of brand attachment and customer trust. Journal of Hospitality and Tourism Management, 44, 184-192. https://doi.org/10.1016/j.jhtm.2020.06.015.

Louis, D., and Lombart, C. (2010). Impact of brand personality on three major relational consequences (trust, attachment, and commitment to the brand). Journal of Product \& Brand Management, 19(2), 114-130. https://doi.org/10.1108/10610421011033467.

Loureiro, S.M.C., Costa, I., and Panchapakesan, P. (2017). A passion for fashion: The impact of social influence, vanity, and exhibitionism on consumer behavior. International Journal of Retail \& Distribution Management, 45(5), 468-484. https://doi.org/10.1108/IJRDM-11-2016-0202.

Manzo, L.C. (2003). Beyond house and haven: Toward a revisioning of emotional relationships with places. Journal of Environmental Psychology, 23(1), 47-61. https://doi.org/10.1016/S0272-4944(02)00074-9.

Mazar, N., Amir, O., and Ariely, D. (2008). The dishonesty of honest people: A theory of self-concept maintenance. Journal of Marketing Research, 45(6), 633-644. https://doi.org/10.1509/jmkr.45.6.633.

Nagy, P., and Koles, B. (2014). "My avatar and her beloved possession": characteristics of attachment to virtual objects. Psychology \& Marketing, 31(12), 1122-1135. https://doi.org/10.1002/mar.20759.

Pathan, Z.H., Jianqiu, Z., Gilal, F.G., and Salam, S. (2017). Linking ICT utilization to SME's performance: miracle or mirage? The empirical evidence and lesson from Pakistan. International Journal of Information Systems and Change Management, 9(2), 149-166.

https://doi.org/10.1504/IJISCM.2017.087987. 
Paul, J. (2015). Masstige marketing redefined and mapped. Introducing a Pyramid Model and MMS measure. Marketing Intelligence and Planning, 33(5), 691-706. https://doi.org/10.1108/MIP-02-2014-0028.

Paul, J. (2019). Masstige model and measure for brand management. European Management Journal, 37(3), 299-312. https://doi.org/10.1016/j.emj.2018.07.003.

Pleshko, L.P., and Heiens, R.A. (2015). Customer satisfaction and loyalty in the Kuwaiti retail services market: why are satisfied buyers not always loyal buyers?. The International Review of Retail, Distribution and Consumer Research, 25(1), 55-71.

https://doi.org/10.1080/09593969.2014.880936.

Pourazad, N., and Pare, V. (2015, April). Conceptualizing the Behavioural Effects of Brand Passion among Fast Fashion Young Customers. Proceedings of Sydney international business research conference, University of Western Sydney Campbelltown, Australia, 17-19 April.

Preacher, K.J., Rucker, D.D., and Hayes, A.F. (2007). Addressing moderated mediation hypotheses: Theory, methods, and prescriptions. Multivariate Behavioral Research, 42(1), 185-227. https://doi.org/10.1080/00273170701341316.

Raza, M.A., Ahad, M.A., Shafqat, M.A., Aurangzaib, M., and Rizwan, M. (2014). The Determinants of Purchase Intention towards Counterfeit Mobile Phones in Pakistan. Journal of Public Administration and Governance, 4(3), 1-19. https://doi.org/10.5296/jpag.v4i3.5846.

Reio Jr, T.G., and Shuck, B. (2015). Exploratory factor analysis: implications for theory, research, and practice. Advances in Developing Human Resources, 17(1), 12-25. https://doi.org/10.1177/1523422314559804.

Rizwan, M., Jamal, M.N., Zareen, K.G., Khan, A., Farhat, B., and Khan, R. (2013). The determinants of purchase intention towards counterfeit mobile phones in Pakistan. Asian Journal of Empirical Research, 3(2), 220-236.

Russo, I., Confente, I., Gligor, D.M., and Autry, C.W. (2016). To be or not to be (loyal): Is there a recipe for customer loyalty in the B2B context?. Journal of Business Research, 69(2), 888-896. https://doi.org/10.1016/j.jbusres.2015.07.002.

Schmalz, S., and Orth, U.R. (2012). Brand attachment and consumer emotional response to unethical firm behavior. Psychology \& Marketing, 29(11), 869-884. https://doi.org/10.1002/mar.20570.

Schultz, S.E., Kleine, R.E., and Kernan, J.B. (1989). 'These are a few of my favorite things:' Toward an explication of attachment as a consumer behavior construct. Advances in Consumer Research, 16(1), 359-366.

Shah, S.S.H., Aziz, J., Jaffari, A.R., Waris, S., Ejaz, W., Fatima, M., and Sherazi, S.K. (2012). The impact of brands on consumer purchase intentions. Asian Journal of Business Management, 4(2), 105-110.

Stewart, K., Kammer-Kerwick, M., Auchter, A., Koh, H.E., Dunn, M.E., and Cunningham, I. (2019). Examining digital video advertising (DVA) effectiveness: The role of product category, product involvement, and device. European Journal of Marketing, 53(11), 2451-2479. https://doi.org/10.1108/EJM-11-2016-0619.

Suh, J.C., and Youjae, Y. (2006). When brand attitudes affect the customer satisfaction-loyalty relation: the moderating role of product involvement. Journal of Consumer Psychology, 16(2), 145-155. https://doi.org/10.1207/s15327663jcp1602_5.

Swimberghe, K.R., Astakhova, M., and Wooldridge, B.R. (2014). A new dualistic approach to brand passion: Harmonious and obsessive. Journal of Business Research, 67(12), 2657-2665. https://doi.org/10.1016/j.jbusres.2014.04.003.

Thomson, M. (2006). Human brands: Investigating antecedents to consumers' strong attachments to celebrities. Journal of Marketing, 70(3), 104-119. https://doi.org/10.1509/jmkg.70.3.104. 
Thomson, M., MacInnis, D.J., and Whan Park, C. (2005). The ties that bind: Measuring the strength of consumers' emotional attachments to brands. Journal of Consumer Psychology, 15(1), 77-91. https://doi.org/10.1207/s15327663jcp1501_10.

Vajarodaya, C., and Fernando, M.S.C.L. (2017). Factors Influencing Purchase Intention towards a Retail Clothing Company. International Research E-Journal on Business and Economics, 3(1), 1-11.

Vallerand, R.J., Blanchard, C., Mageau, G.A., Koestner, R., Ratelle, C., Léonard, M., and Marsolais, J. (2003). Les passions de l'ame: on obsessive and harmonious passion. Journal of Personality and Social Psychology, 85(4), 756-767. https://doi.org/10.1037/0022-3514.85.4.756.

Vlachos, P.A., and Vrechopoulos, A.P. (2012). Consumer-retailer love and attachment: Antecedents and personality moderators. Journal of Retailing and Consumer Services, 19(2), 218-228. https://doi.org/10.1016/j.jretconser.2012.01.003.

Vlachos, P.A., Theotokis, A., Pramatari, K., and Vrechopoulos, A. (2010). Consumer-retailer emotional attachment: Some antecedents and the moderating role of attachment anxiety. European Journal of Marketing, 44(9/10), 1478-1499. https://doi.org/10.1108/03090561011062934.

Wallendorf, M., and Arnould, E.J. (1988). "My favorite things:” A cross-cultural inquiry into object attachment, possessiveness, and social linkage. Journal of Consumer Research, 14(4), 531-547. https://doi.org/10.1086/209134.

Whan Park, C., MacInnis, D.J., Priester, J., Eisingerich, A.B., and Iacobucci, D. (2010). Brand attachment and brand attitude strength: Conceptual and empirical differentiation of two critical brand equity drivers. Journal of Marketing, 74(6), 1-17. https://doi.org/10.1509/jmkg.74.6.1.

White, R.C., Voorhees, C.M., Bourdeau, B.L., and Hoppner, J.J. (2016). None of the Glory: The Implications of Customer Attributions of Credit in Successful Co-Productive Service Experiences. In Looking Forward, Looking Back: Drawing on the Past to Shape the Future of Marketing (pp. 267-270). Springer, Cham. https://doi.org/10.1007/978-3-319-24184-5_70.

Williams, D.R., Patterson, M.E., Roggenbuck, J.W., and Watson, A.E. (1992). Beyond the commodity metaphor: Examining emotional and symbolic attachment to place. Leisure Sciences, 14(1), 29-46. https://doi.org/10.1080/01490409209513155.

Xixiang, S., Gilal, R.G., and Gilal, F.G. (2016). Brand experience as a contemporary source of brand equity in the $21^{\text {st }}$ century: evidence from the Chinese consumer market. International Journal of Education Research, 4(9), 63-76.

Yoo, B., and Lee, S.H. (2009). Buy genuine luxury fashion products or counterfeits? ACR North American Advances.

Zasloff, R.L. (1996). Measuring attachment to companion animals: a dog is not a cat is not a bird. Applied Animal Behaviour Science, 47(1-2), 43-48. https://doi.org/10.1016/0168-1591(95)01009-2. 